\title{
Bubbling with Excitement: An Experiment
}

\author{
Eduardo B. Andrade \\ Brazilian School of Public and Business Administration \\ Fundação Getulio Vargas, Rio de Janeiro \\ Terrance Odean \\ Haas School of Business \\ University of California, Berkeley \\ Shengle Lin \\ College of Business \\ San Francisco State University
}

October 2014

\begin{abstract}
*We are grateful for financial support from the Coleman Fung Risk Management Research Center and from the UC Berkeley Xlab. We also thank the Xlab for their assistance with data collection. We thank Richard Deaves, Alok Kumar, Markku Kaustia, and seminar participants at the University of Stavanger, McMaster University, Notre Dame, the University of Michigan, the Q Group, UC San Diego, the Instituto Tecnológico Autónomo de México (ITAM) Finance Conference, the Helsinki Finance Conference, the Experimental Finance Conference at the University of Luxembourg, the Vienna University of Economics and Business, NYU, Tulane University, and Princeton University for comments. We thank Paola Sapienza for providing a video clip for one of our experiments.
\end{abstract}




\title{
Bubbling with Excitement: An Experiment
}

\begin{abstract}
Anecdotal and indirect empirical evidence suggest that excitement and market bubbles are intertwined, such that excitement not only arises during bubbles but may also help fuel them. We directly test the impact of excitement on bubbles in an experimental assetpricing market chosen to generate bubbles. Participants take part in a laboratory market in which they trade a risky asset over a computer network. Prior to trading, they are assigned to emotion inductions (i.e., video clips meant to trigger particular emotional states). The average magnitude and amplitude of bubbles in the excitement treatment are compared those in two alternative treatments - calm and fear. The results of 55 markets (495 participants in total) show larger asset pricing bubbles in the excitement treatment relative to the other two treatments.
\end{abstract}


From "tulipmania" of 1637 to the "irrational exuberance" of the late 1990s, popular accounts emphasize the role of emotions, and excitement in particular, on investment bubbles. However, there is no direct evidence in the literature demonstrating the causal impact of this pleasantly intense emotion on asset-pricing bubbles.

During the run-up of a bubble, an investor who is earning unusually and unexpectedly large returns is likely to experience excitement. This excitement may trigger excitement in others (Parkinson and Simons, 2009). Excitement and other emotions influence behavior directly and also through their impact on judgments of expected consequences (Lowenstein and Lerner, 2003). Furthermore, "as emotions intensify, they exert and ever-increasing influence on behavior" (Lowenstein and Lerner, 2003).

We posit that excitement changes behavior in such a way as to magnify the size of asset pricing bubbles. We test this conjecture in a bubble-prone experimental market setting (Caginalp, Porter, and Smith, 2001). While we also believe that real world bubbles can generate excitement, we do not test this. Nor do we claim that excitement alone can generate bubbles.

While the histories of asset pricing bubbles suggest that investors become excited during bubbles, it is difficult to make causal inferences about the role of emotions in bubbles from field data. And, somewhat surprising, the vast majority of experimental studies of asset pricing bubbles have focused on non-emotional factors such as liquidity, experience, transparency, novelty of environment, and speculation (Caginalp, Porter, and Smith, 2001; Dufwenberg, Lindqvist, and Moore, 2005; Hussam, Porter, and Smith, 2008; Lei, Noussair, and Plott, 2001). This paper reports results from laboratory financial 
market experiments designed to induce and, hence, directly test the impact of, this pleasantly intense emotion on asset-pricing bubbles.

In a series of experimental markets, we induce participants' incidental emotional states with video clips, a standard procedure (Rottenberg, Ray, and Gross 2007) that is known to impact financial and economic decision-making (Andrade and Ariely 2009; Guiso, Sapienza, and Zingales, 2013). After the incidental emotion induction, participants take part in a financial market simulation previously shown to generate bubbles. Bubbles in the "excitement" treatment are measured and compared to bubbles in two other treatments. These two additional treatments vary in either valence or intensity: a highintensity, negative-valence treatment (i.e., "fear") and a low-intensity, positive-valence treatment (i.e., “calm”).

As expected and consistent with Caginalp, Porter, and Smith's (2001) results, we observe bubbles across all three emotion treatments. However, significant differences are observed across treatments. Our results show first and foremost that excitement produces larger asset-pricing bubbles in experimental markets when compared to both the fear and the calm treatments. The differences in the magnitudes and peak amplitudes of the bubbles are both large and statistically significant. Further, in the excitement treatment bubbles begin to form in the first round of trading while in the calm and fear treatments they do not. However, fear and excitement treatments share some commonalities. Subsequent to the first round of trading, bubbles grow as much in the fear treatment as in the excitement treatment and significantly more so than in the calm treatment. That is, in these bubble-prone markets, while the fear treatment initially suppresses bubble formation, the suppression is short lived. 
The rest of this paper is organized as follows. In the next section we discuss related research. We describe our experimental design in Section II. We present results in Section III, followed by concluding remarks.

\section{Related Research}

Bubbles in experimental asset markets were first documented by Smith, Suchanek, and Williams (1988). Subsequent studies have documented that bubbles are greater when traders are endowed with more cash relative to risky assets, when dividends are paid after each round of trading rather than at the end of trading, and when traders can buy on margin (Caginalp, Porter, and Smith, 2001). Bubbles may be dampened or eliminated when short selling is allowed though this is not the case for all experimental designs (King, Smith, Williams, and Van Boening, 1993; Haruvy and Noussair, 2004; Ackert, Charupat, Church, and Deaves, 2006). Bubbles are smaller traders are asymmetrically informed about future dividends (Sutter, Huber, and Kirchler, 2012). Bubbles are greater when the distribution of dividends is more lottery-like (Ackert, Charupat, Church, and Deaves, 2006), but can arise even when dividends are nonstochastic (Porter and Smith, 1995). Bubbles are dampened or eliminated when some or all traders are experienced (Dufwenberg, Lindqvist, and Moore, 2005); however, even experienced traders may generate bubbles when market parameters change (Hussam, Porter, and Smith, 2008). Bubbles in one experimental asset may engender bubbles of similar magnitude in simultaneously traded assets (Fisher and Kelly, 2000).

One explanation as to why traders in experimental markets buy at above fundamental value is that they expect to be able to sell the asset at a yet higher price. However, Lei, Noussair, and Plott (2001), find that bubbles can arise in markets in which 
buyers cannot resell and, thus, speculation is not feasible. Schoenberg and Haruvy (2010) find greater bubbles when traders are given periodic performance information about the best performing trader. Kirchler, Huber, and Stöckl (2012) argue that bubbles arise in markets where the asset has a declining fundamental value because traders do not fully understand the process. Noussair, Robin and Ruffieux (2001) generate bubbles in markets with constant fundamental values.

An emotional account suggests that intense pleasant emotions arise in bullish markets, which can in turn sustain and inflate a bubble, forming a feedback loop. Direct empirical evidence indeed indicates an increase in pleasantness (unpleasantness) as investors make (lose) money (Lo, Repin, and Steenbarger 2005). Further, proxies of emotional/mood states (e.g., the weather) have shown to correlate with stock market prices. Hirshleifer and Shumway (2003) demonstrate that sunshine is correlated with stock returns. Kamstra, Kramer, and Levi (2003) show that stock returns are lower when daylight is decreasing. Bassi, Colacito, and Fulghieri (2012) provide experimental evidence that sunshine promotes risk taking, possibly mediated by sunshine's effect on mood.

Positive affect (Isen and Patrick 1983) and excitement in particular (Kuhnen and Knutson 2011) have shown to increase risk taking, whereas negative affect, particularly fear and anxiety, have shown to increase risk aversion (Guiso, Sapienza, and Zingales 2013; Kuhnen and Knutson 2011; Lee and Andrade 2011). None of these findings, however, directly test whether emotions can inflate or dampen a bubble. Lahav and Meer (2010) induce positive and neutral mood prior to experimental markets to assess its impact on bubbles. Unfortunately, given the reduced sample size per treatment $(n=2)$, any statistical inference from that study is rather limited. 
In this manuscript, we test whether excitement, a positive valence intense emotion likely to arise during a financial bubble, may inflate or deflate a bubble relative to two alternative treatments. Valence and intensity represent the dominant dimensions of an emotion experience (Barrett 2006; Lang, Greenwald, Bradley, and Hamm, 1993; Barrett and Russell, 1999), and excitement is characterized by a pleasantly intense emotional state (Russell 1980). We thus compare the effects of excitement to the effects of two alternative treatments: one of similar intensity but of negative valence (i.e., fear) and one of similar valence but of much lower intensity (i.e., calm). Thus, our alternative emotional treatments represent the "flip-sides" of excitement in either intensity or valence (Russell 1980). We manipulate participants' emotions prior to the beginning of an experimental market and assess the impact of the induced emotion treatment on the asset-pricing market.

\section{Experimental Design}

Four hundred ninety five participants were recruited from UC Berkeley's Xlab student subject pool. No participant took part in more than one experiment. Participants were paid a $\$ 5$ show-up fee and an additional performance based fee averaging $\$ 21.68$.

Our experimental market is modeled on those of Smith, Suchanek, and Williams (1988) and Caginalp, Porter, and Smith (2001). A security with a finite life of 15 rounds is traded in a continuous double auction. After each round of trading the asset pays a random dividend drawn from a uniform distribution with four potential outcomes of 0,8 , 
28, and 60 cents. ${ }^{1}$ Thus, the expected dividend in each round is 24 cents and the fundamental value of the asset - i.e., the expected value of remaining dividends - is $\$ 3.60$ prior to the first round of trading and declines by 24 cents each round. At the end of 15 rounds of trading the asset expires worthless. The distribution of dividends is known to all traders and the current fundamental value of the asset is displayed on each trader's computer screen. Traders also see all currently posted offers to buy and to sell. Our initial endowments, dividend distribution policy, and open order book match those used by Caginalp, Porter, and Smith (2001) in their treatment designed to maximize bubbles (See Appendix A).

Nine participants trade in each market; no participant traded in more than one market. Three traders receive an initial endowment of $\$ 18.00$ plus 1 share of the risky asset; three traders receive $\$ 14.40$ plus 2 shares; three traders receive $\$ 10.80$ plus 3 shares. After completing three practice rounds of trading, participants are asked to watch a video lasting approximately 5 minutes while the experimenter prepares for the actual experiment. Participants are told, "Because the waiting is a bit long, we will play a video clip. Since we intend to use video clips in another experiment, we've selected a few different video clips. After you've finished watching the clip, please answer a few questions about it. Note that the video is not related to your earnings today. So thank you in advance for helping out." After watching the video clip, participants answer two short questions about their emotional state and about the main purpose of the study. They then begin the trading sessions. ${ }^{2}$

\footnotetext{
${ }^{1}$ To facilitate comparisons across experimental markets, one random dividend sequence $(8,60,28,8,60$, $8,0,28,0,60,28,60,0,8,8)$ was drawn for the first market and then used for all subsequent markets.

${ }^{2}$ In a post-experiment survey, only $2.2 \%$ of participants correctly guessed the intended purpose of the experiment.
} 
To test whether excitement will produce larger bubbles relative to the other two emotion treatments, each experimental market is preceded by a video clip meant to induce a given emotional state. We ran series of 55 experimental markets (9 per market) distributed as follows: 24 excitement, 15 calm, and 16 fear treatments. ${ }^{3}$ For the sake of robustness and to avoid the potential idiosyncrasies of each clip video, two different video clips were used for each emotion type (excitement: Knight \& Day and Mr. \& Mrs. Smith; fear: Hostel and Salem's Lot; calm: Franklin and Peace in the Water).

\section{Results}

Our underlying motivation is the hypothesis that, once started, real world bubbles generate excitement and that excitement further inflates and sustains the bubble. We do not claim that excitement alone creates bubbles. To better match our experiment to our motivation, we choose experimental market conditions that have been previously shown to generate bubbles. As expected, we observe bubbles across all three emotion treatments. This is consistent with Caginalp, Porter, and Smith (2001) results when they used the same endowments, dividend distribution policy, and order-book transparency that we use. Of importance, the bubbles vary as a function of the emotion treatment induced prior to the asset-pricing market (see Figure 1).

To compare the effects of excitement, fear, and calm emotions on bubbles we analyze two metrics of asset pricing bubbles, magnitude and peak amplitude:

\footnotetext{
${ }^{3}$ We ran 24 excitement treatment markets before completing all the calm and fear treatment markets. Because of the high cost of the experiments we decided to run only 16 calm and 16 fear treatment markets. However, we were unable to run the $16^{\text {th }}$ calm treatment market because it was scheduled at end of a semester and not enough participants were available for the experiment. We also ran 8 extra markets preceded by a mix of 2 sad video clips. Given the small sample size of this "sad" treatment and for the sake of simplicity, we have excluded them from the main analyses. The inclusion of this condition does not change in any way the main conclusions of the paper. The sad treatment produced bubbles between the calm and fear treatments and significantly lower than the excitement treatment in both magnitude and peak amplitude.
} 
1. Magnitude measures the average difference in the price of the risky asset and its fundamental value across the fifteen rounds of trading. Magnitude is calculated as Magnitude $=\frac{1}{15} \sum_{r=1}^{15}\left(\bar{P}_{r}-f_{r}\right)$ where $\bar{P}_{r}$ is the average volume weighted transaction price in trading round $r$ and $f_{r}$ is the fundamental value (i.e., the expected value of remaining dividends) in trading round $r{ }^{4}$

2. Peak amplitude measures the maximum difference in the price of the risky asset and its fundamental value across the fifteen rounds of trading. Peak amplitude is calculated as Peak Amplitude $=\max _{r \in(1,15)}\left\{\bar{P}_{r}-f_{r}\right\}$ where $\bar{P}_{r}$ is the average volume weighted transaction price in trading round $r$, and $f_{r}$ is the fundamental value (i.e., the expected value of remaining dividends) in trading round $r^{5}$.

Table 1, Panel A reports the average magnitude of bubbles across markets by emotion treatment. The average magnitude of the bubbles after participants are induced to feel excited (292.0) is much greater than the average magnitude of bubbles after the participants are induced to feel calm (163.3) or fear (218.2). We formally test for differences in magnitude and amplitude of bubbles under our treatments, with a two-

\footnotetext{
${ }^{4}$ Since the average fundamental value in each experiment is the same, regardless of treatment, our magnitude measure is equivalent to the Relative Deviation (RD) measure of bubbles in experimental markets proposed by Stöckl, Huber, and Kirchler (2010) and can be converted to RD by dividing by 192 .

${ }^{5}$ Some authors calculate a trough -to-peak amplitude measure that subtracts the minimum difference of price and fundamental value from the maximum difference (e.g., Porter and Smith (1995), Hussam et al. (2008), Noussair et. al. (2001)). As Stöckl, Huber, and Kirchler (2010) point out, this measure treats undervaluation and overvaluations as equally contributing to a bubble. Thus a market with a price rise from $50 \%$ below fundament value to fundamental value and a market with a price rise from fundamental value to $50 \%$ above fundamental value are considered to experience equivalent bubbles. Our peak amplitude statistic measures only how high prices (the average price in a trading round) rise above fundamental values.
} 
sample two-tailed t-test with equal variances and with a two-sample Wilcoxon rank-sum (Mann-Whitney) test. For both tests, the magnitude of bubbles under the excitement condition is great than that under the other two treatments. We reject the null hypothesis magnitude $($ excitement $)=$ magnitude $($ calm $)$ with $\mathrm{t}=5.38, \mathrm{p}<0.001(\mathrm{t}$ test $)$ and $\mathrm{z}=4.22, \mathrm{p}$ $<0.001$ (rank sum test). We reject the null hypothesis magnitude(excitement) $=$ magnitude(fear) with $\mathrm{t}=2.51, \mathrm{p}<0.02$ (2-tailed $\mathrm{t}$ test) and $\mathrm{z}=2.37, \mathrm{p}<0.02$ (rank sum test). We cannot reject the null hypothesis magnitude(calm) $=$ magnitude(fear) with $t=$ $1.90, \mathrm{p}<0.07$ (2-tailed t test) and $\mathrm{z}=1.78, \mathrm{p}<0.08$ (rank sum test).

Table 1, Panel B reports the average peak amplitude of bubbles across markets by emotion treatment. The average peak amplitude of the bubbles after participants are induced to feel excited (512.3) is much greater than the average amplitude of bubbles after the participants are induced to feel calm (332.3) or fear (414.7). Again, for both tests, the peak amplitude of bubbles under the excitement treatment is greater than that under the calm and fear treatments. We reject the null hypothesis peak amplitude $($ excitement $)=$ peak amplitude $($ calm $)$ with $\mathrm{t}=4.01, \mathrm{p}<0.001$ (2-tailed $\mathrm{t}$ test) and $\mathrm{z}=3.66, \mathrm{p}<0.001$ (rank sum test). We reject the null hypothesis peak amplitude (excitement $)=$ peak amplitude $($ fear $)$ with $\mathrm{t}=2.04, \mathrm{p}<0.05$ (2-tailed $\mathrm{t}$ test $)$ and $\mathrm{z}$ $=1.93, \mathrm{p}<0.06$ (rank sum test). We cannot reject the null hypothesis peak amplitude $($ calm $)=$ peak amplitude(fear) with $\mathrm{t}=1.78, \mathrm{p}=0.086$ (2-tailed $\mathrm{t}$ test) and $\mathrm{z}=$ $1.38, \mathrm{p}=0.167$ (rank sum test).

An examination of Figure 1, shows that (1) for the excitement treatment, the average price in the first round is well above fundamental value while for the calm and fear treatments first round prices are approximately the same as fundamental value, and (2) subsequent to round 1, prices in the fear treatment rise at about as much as prices in 
the excitement treatment and much more than in the calm treatment.

To formally test these observations, we analyze two additional metrics, Round 1 Amplitude, and Peak Amplitude minus Round 1 Amplitude:

3. Round 1 Amplitude measures the difference between the average price of the risky asset and its fundamental value in the first round of trading. Round 1 Amplitude is calculated as where $\overline{P_{1}}$ is the average volume weighted transaction price in trading round 1 , and $f_{1}$ is the fundamental value (i.e., the expected value of remaining dividends) in trading round 1.

4. Peak Amplitude - Round 1 Amplitude. This measures the maximum increase in the amplitude of the bubble subsequent to the first round of trading.

Table 1, Panel $\mathrm{C}$ reports the amplitude of bubbles in round 1 across markets by emotion treatment. The Round 1 Amplitude of the bubbles after participants are induced to feel excited (72.0) is large and statistically greater than $0(p<0.0012$-sided $t$ test $)$. It is also much greater than the Round 1 Amplitude of bubbles after the participants are induced to feel calm (10.9) or fear (4.0). We reject the null hypothesis Round 1 Peak Amplitude $($ excitement $)=$ Round 1 Amplitude $($ calm $) \mathrm{t}=2.28, \mathrm{p}<0.03$ (2-tailed t test) and $\mathrm{z}=2.11, \mathrm{p}<0.04$ (rank sum test). We reject the null hypothesis Round 1 Amplitude(excitement) $=$ Round 1 Amplitude(fear) $\mathrm{t}=2.14, \mathrm{p}<0.04$ (2-tailed t test) but cannot reject with the Mann-Whitney test $(z=1.64, \mathrm{p}=.10)$. We cannot reject the null hypothesis that Round 1 Amplitude $($ calm $)=0$, Round 1 Amplitude $($ fear $)=0$, or Round 1 Amplitude $($ calm $)=$ Round 1 Amplitude(fear).

Table 1, Panel D reports the (Peak Amplitude - Round 1 Amplitude). The means 
of (Peak Amplitude - Round 1 Amplitude) are very similar after participants are induced to feel excited (440.3) and fear (410.7). We cannot reject the null hypothesis that (Peak Amplitude - Round 1) $($ exciting $)=($ Peak Amplitude - Round 1$)($ fear $)(\mathrm{t}$ test $\mathrm{p}=0.52$, Whitney-Mann, $\mathrm{p}=0.89$ ). However, the means of (Peak Amplitude - Round 1 Amplitude) are quite a bit lower after participants are induced to feel calm (321.4). We reject the null hypothesis $($ Peak Amplitude - Round 1) $($ exciting $)=($ Peak Amplitude Round 1)(calm) $\mathrm{t}=2.44, \mathrm{p}<0.02$ (2-tailed $\mathrm{t}$ test), $\mathrm{z}=2.28, \mathrm{p}<0.03$ (rank sum test) and we reject the null hypothesis $($ Peak Amplitude - Round 1$)($ fear $)=($ Peak Amplitude Round 1) $($ calm $) \mathrm{t}=2.26, \mathrm{p}<0.04$ (2-tailed t test), $\mathrm{z}=2.10, \mathrm{p}<0.04$ (rank sum test).

To summarize, the magnitude and peak amplitude of bubbles are large and statistically significant in all three treatments $(\mathrm{p}<0.001)$. This was anticipated based on the choice of market parameters and prior work by Caginalp, Porter, and Smith (2001). The magnitude and peak amplitude in the excitement treatment are substantially and statistically larger than in the calm and fear treatments. In the first round of trading, prices rise well above fundamental value in the excitement treatment but do not do so in the calm or fear treatment. Over the next 14 rounds of trading, prices rise similarly in the excitement and fear treatments and significantly more so than in the calm treatment.

\section{Emotion Induction Check}

To assess the extent to which the video clips varied in valence, intensity, and emotion type as expected, we conducted an independent test of the emotion inductions. One hundred eighty five participants were recruited in an online platform (Amazon Mechanical Turk) and randomly assigned to one of the video clips. They were paid \$1 each for their participation in this study. After watching the video clip, participants 
reported their emotional reactions on an adapted version of the Self-Assessment Manikin (SAM), a 2-item scale widely used to measure the valence and intensity of emotional reactions to stimuli (Bradley and Lang 1994). They were then asked to indicate the type of emotion experience that best captured what they were feeling ("The movie clip made me feel... _. Afraid/Scared/Anxious, _ _ Excited/Eager/Enthusiastic, _Calm/Relaxed/Peaceful,__ etc.; see Appendix B).

Table 2 Panels A and B report the statistical differences between the excitement treatments and the calm and fear treatments on valence and intensity, respectively. Panel C displays the distribution of emotion types per video clip ${ }^{6}$. The results show, as expected, that the video clips triggered emotional reactions of different valence and intensity. Participants indicated that both Knight and Day and Mr. and Mrs. Smith triggered positive (Panel A) and relatively intense (Panel B) emotional reactions. Also, "excited/eager/enthusiastic" was the most cited emotional reaction to those two video clips (Panel C). Franklin and Peace in the Water also triggered positive emotional reactions; they were, however, much lower in intensity when compared to the excitement video clips. Consistently, "calm/relaxed/peaceful" was the most cited emotional reaction. Finally, Hostel and Salem's Lot were at least as intense as the excitement videos, but were also clearly negative experiences. Further, "afraid/scared/anxious" represented the most cited emotional reactions.

\section{Discussion}

An advantage of the Smith, Suchanek, and Williams (1988) experimental setting is that it has been well studied. It is well known, for example, that bubbles are more likely

\footnotetext{
${ }^{6}$ The significance levels reported in the table are from 2 tailed t-tests. P-values are similar for rank-sum tests.
} 
when traders are endowed with more cash relative to risky assets, when dividends are paid after each round of trading rather than at the end of trading, when the order book is transparent, and when traders can buy on margin (Caginalp, Porter, and Smith, 2001). While we do not permit buying on margin, our allocations are cash rich-matching the cash rich (CR) endowments employed by Caginalp, Porter, and Smith (2001), dividends are paid after every round, and the order book is viewed by all participants; this is likely why we get bubbles in most experiments regardless of treatment.

As noted above, several features of the Smith, Suchanek, and Williams (1988) experimental setting have been criticized. In our experiments, criticized features of the experimental setting such as declining fundamental value, short sale constraints, and inexperienced traders, are held constant across treatments. Thus, while these features may, in part, explain why bubbles arise in this setting, they do not explain our main finding that bubbles are significantly larger when participants begin trading in a pleasantly intense emotional state.

Our main finding is that excitement inflates bubbles compared to two alternative treatments: one of similar intensity but of negative valence (i.e., fear) and one of similar valence but of much lower intensity (i.e., calm). The differences in the magnitude and amplitude of the bubbles are both economic and statistically significant. In the excitement treatment bubbles begin to form in the first round of trading while in the calm and fear treatments they do not. Interestingly, subsequent to the first round of trading, bubbles grow as much in the fear treatment as in the excitement treatment and significantly more so than in the calm treatment. That is, while the fear treatment initially suppresses bubble formation, the suppression is short lived in a "bubble-prone" market setting. 
From a theoretical and empirical standpoint, fear represents a particularly interesting comparison treatment. As bubbles climb, some investors may fear that prices will collapse causing losses. Such fear is most likely to be felt by investors still in the market, some of whom may even vacillate between fear and excitement. So, fear can reduce a bubble relative to, at least, the excitement treatment.

However, fear, like excitement, is a high intensity — though negative-emotion. Intense emotions are physiologically arousing. Contextual cues are known to influence how people interpret arousing events (Schachter and Singer, 1962) and emotional arousal (e.g., fear as sexual attraction, Dutton and Aron, 1974). Lee and Andrade (2014), for instance, find that experimental participants who are manipulated to experience fear become excited while playing a casino-like game. In short, previous research has found that fear can turn to excitement when contextual cues suggest excitement and do not reinforce fear.

To better match our experiment to our motivation, we choose experimental market conditions that have been previously shown to generate bubbles. Our bubbleprone market experiment does not reinforce the fear but does reinforce excitement. Put simply, in our fear treatment, contextual cues and emotions are not aligned whereas in the excitement treatment, contextual cues and emotions are aligned. The latter is likely to be true not only in the lab but also in real markets. Real world investors who are unexpectedly profiting from rapidly rising prices are likely to become excited and to remain excited as prices continue to rise.

In the same way that we have shown that excitement fuels a bubble, future research could investigate the extent to which fear than further dampen "crash-prone" markets. 


\section{Conclusion}

Historical accounts suggest that rapid, unexpected increased in wealth during the appreciation phase of asset pricing bubbles can lead investors to experience intense, positive emotions. We document, in an experimental setting, that magnitude and amplitude of bubbles is greater when, prior to trading, traders experience the highintensity, positive emotion of excitement than when they experience either the lowintensity, positive emotion of calm or the high-intensity, negative emotion of fear. Thus the excitement generated by rapidly rising prices in real world markets may trigger emotions that lead to larger asset pricing bubbles.

\section{References}

Andrade, Eduardo B. and Dan Ariely, 2009, The Enduring Impact of Transient Emotions on Decision Making, Organizational Behavior and Human Decision Processes, 109 (May), 1-8.

Ackert, Lucy, Narat Charupat, Bryan Church, and Richard Deaves, 2006, Margin, Short Selling, and Lotteries in Experimental Asset Markets, Southern Economic Journal, 73, 419-436.

Barrett, Lisa. F., and James A. Russell, 1999, Structure of Current Affect, Current Directions in Psychological Science, 8, 10-14.

Barrett, Lisa. F. 2006, Valence as a Basic Building Block of Emotional Life, Journal of Research in Personality, 40, 35-55.

Bassi, Anna, Riccardo Colacito, and Paolo Fulghieri, 2013, O Sole Mio. An Experimental Analysis of Weather and Risk Attitudes in Financial Decisions, Review of Financial Studies, 26(7), 1824-1852.

Capinalp, Gunduz, David Porter, and Vernon Smith, 2001, Financial Bubbles: Excess Cash, Momentum, and Incomplete Information, Journal of Psychology and Financial Markets, 2, 80-99.

Dufwenberg, Martin, Tobias Lindqvist, and Evan Moore, 2005, Bubbles and Experience: 
An Experiment, American Economic Review, 95, 1731-1737.

Dutton, Donald and Arthur Aron, 1974, Some Evidence for Heightened Sexual Attraction under Conditions of High Anxiety, Journal of Personality and Social Psychology, $30,510-517$.

Fisher, Eric, and Frank Kelly, 2000, Experimental Foreign Exchange Markets, Pacific Economic Review, 5, 365-387.

Guiso, Luigi, Paola Sapienza, and Luigi Zingales, 2013, Time Varying Risk Aversion, NBER working paper 19284.

Haruvy, Ernan., and Charles N. Noussair, 2006, The Effect of Short Selling on Bubbles and Crashes in Experimental Spot Asset Markets, Journal of Finance, 61, 11191157.

Hirshleifer, David and Tyler Shumway, 2003, Good Day Sunshine: Stock Returns and the Weather, Journal of Finance, 58(3), 1009-1032.

Hussam, Reshmaan, David Porter, and Vernon Smith, 2008, Thar She Blows: Can Bubbles Be Rekindled with Experienced Subjects?, American Economic Review, 98, 924-937.

Isen, Alice M. and Robert Patrick, 1983, The Effect of Positive Feelings on Risk Taking: When the Chips Are Down, Organizational Behavior and Human Performance, 31, 2, 194-202.

Kamstra, Mark J., Lisa A. Kramer, and Maurice D. Levi, 2003, Winter Blues: A SAD Sto ck Market Cycle, American Economic Review, 93(1), 324-343.

King, Ronald, Vernon Smith, Arlington Williams, and Mark Van Boening, 1993, The Robustness of Bubbles and Crashes in Experimental Stock Markets; in Richard Day and Ping Chen eds., Nonlinear Dynamics and Evolutionary Economics, 183200, (Oxford University Press, Oxford).

Kirchler, Michael, Jürgen Huber, and Thomas Stöckl, 2012, Thar She Bursts: Reducing Confusion Reduces Bubbles, American Economic Review, 102(2), 865-83.

Kuhnen, Camelia M. and Brian Knutson, 2011, The Influence of Affect on Beliefs, Preferences, and Financial Decisions, Journal of Financial and Quantitative Analysis, 46(03), 605-626.

Lahav, Yaron and Shireen Meer, 2010, The Effect of Induced Mood on Prices in Experimental Asset Markets, working paper Emory University. 
Lang, Peter. J., Mark K. Greenwald, Margaret M. Bradley, and Alfons O. Hamm, 1993, Looking at Pictures: Affective, Facial, Visceral, and Behavioral Reactions, Psychophysiology, 30, 261-273.

Lee, Chan Jean and Eduardo B. Andrade, 2011, Fear, Social Projection, and Financial Decision Making, Journal of Marketing Research, Special Interdisciplinary Issue on Consumers' Financial Decision Making, XLVII, S121-S129.

Lee, Chan Jean and Eduardo B. Andrade, 2014, Fear, Excitement, and Financial RiskTaking, Cognition and Emotion, online first: doi:10.1080/02699931.2014.898611

Lei, Vivian, Charles N. Noussair, and Charles R. Plott, 2001, Nonspeculative Bubbles in Experimental Asset Markets: Lack of Common Knowledge of Rationality vs. Actual Irrationality, Econometrica, 69, 831-859.

Lo, Andrew W., Dmitry V. Repin, and Brett N. Steenbarger, 2005, Fear and Greed in Financial Markets: A Clinical Study of Day-traders, American Economic Review, 95, 352-359.

Lowenstein, George, and Jennifer S. Lerner, 2003, The Role of Affect in Decision Making. In R. Davidson, K. Scherer, \& H. Goldsmith (Eds.), Handbook of affective science, pp. 619-642. New York: Oxford University Press.

Noussair, Charles, Stephanie Robin and Bernard Ruffieux, 2001, Price Bubbles in Laboratory Asset Markets with Constant Fundamental Values. Experimental Economics, 4, 87-105.

Parkinson, Brian and Gwenda Simons, 2009, Affecting Others: Social Appraisal and Emotion Contagion in Everyday Decision Making. Personality and Social Psychology Bulletin, 35, 1071-1084.

Porter, David, and Vernon Smith, 1995, Futures Contracting and Dividend Uncertainty in Experimental Asset Markets, Journal of Business, 68, 509-541.

Rottenberg, Jonathan, Rebbeca D. Ray, and James J. Gross, 2007, Emotion Elicitation using Films. In James A. Coan and John. J. B. Allen (Eds.), Handbook of emotion elicitation and assessment. New York, NY: Oxford University Press.

Russell, James A., 1980, A Circumplex Model of Affect, Journal of Personality and Social Psychology, 39, 1161-1178.

Schachter, Stanley, and Jerome E. Singer, 1962, Cognitive, Social, and Physiological Determinants of Emotional State, Psychological Review, 69, 379-399.

Schoenberg, Eric and Ernan Haruvy, 2010, Relative Performance Information in Asset Markets: An Experimental Approach, working paper Columbia University. 
Sutter, Matthias, Jürgen Huber, and Michael Kirchler, 2012, Bubbles and Information: An Experiment, Management Science, 2, 384-393.

Stöckl, Thomas, Jürgen Huber, and Michael Kirchler, 2010, Bubble Measures in Experimental Asset Markets, Experimental Economics, 13, 284-298.

Smith, Vernon L., Gerry L. Suchanek, and Arlington W. Williams, 1988, Bubbles, Crashes, and Endogenous Expectations in Experimental Spot Asset Markets, Econometrica, 56, 1119-51. 
Figure 1. Average Prices by Round for Each Treatment (Excitement, Fear, \& Calm) The average trading prices are plotted round-by-round for 24 "Excitement" markets, 16 "Fear" markets and 15 "Calm" markets. The downward sloping straight line plots the declining fundamental values over 15 rounds of trading.

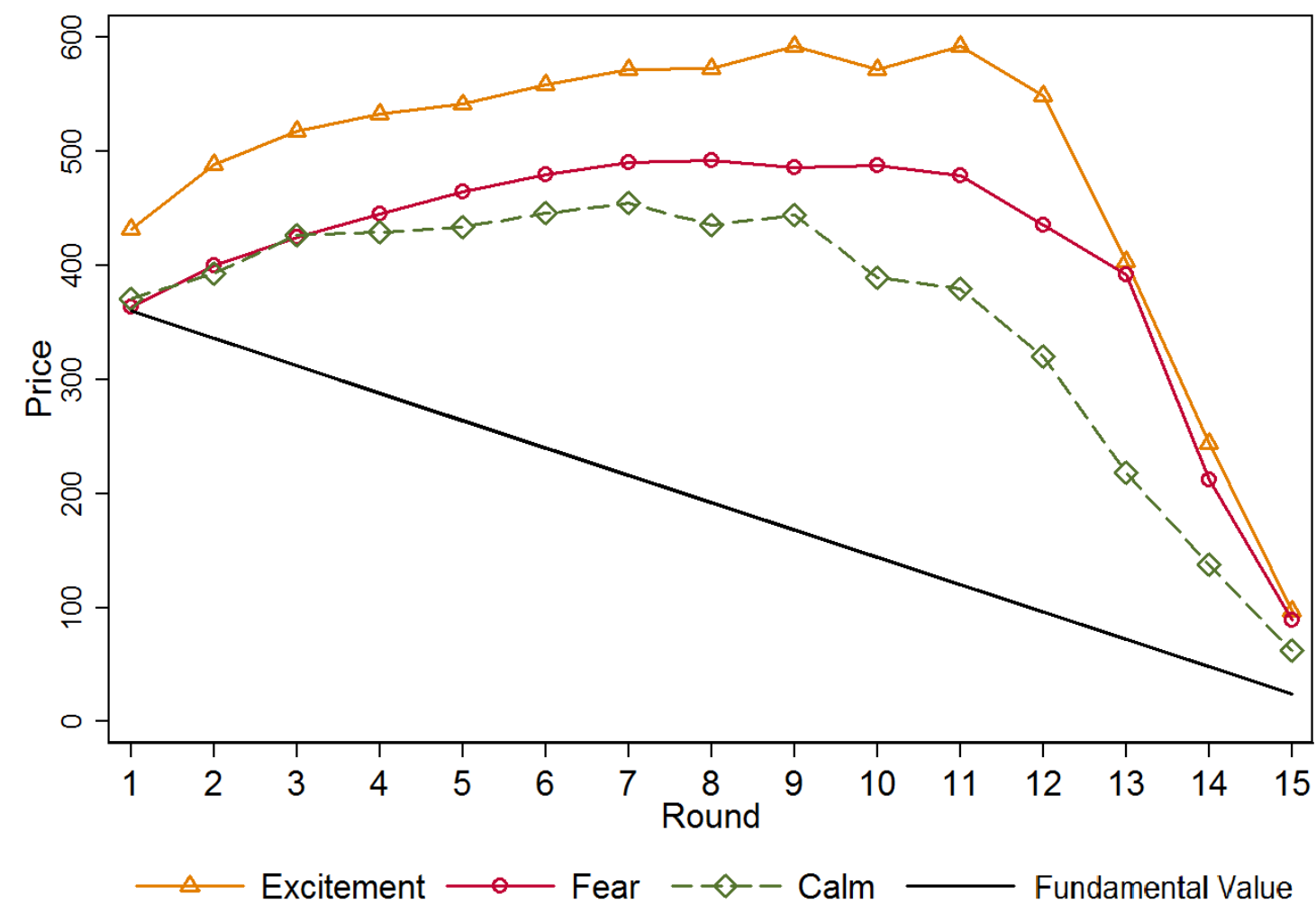


Table 1: Magnitude and Amplitude of Bubbles

Panel A reports the magnitude of bubbles across market experiments by treatment: Magnitude $=\frac{1}{15} \sum_{r=1}^{15}\left(\bar{P}_{r}-f_{r}\right)$, where $\bar{P}_{r}$ is the average transaction price in trading round $r$ and $f_{r}$ is the fundamental value (i.e., the expected value of remaining dividends) in trading round $r$. Panel $\mathrm{B}$ reports the peak amplitude of bubbles across market experiments by treatment: Peak Amplitude $=\max _{r \in(1,15)}\left\{\bar{P}_{r}-f_{r}\right\}$. Panel C reports the amplitude of bubbles in Round 1 across market experiments by treatment: Period 1 Amplitude $=\bar{P}_{1}-f_{1}$. Panel D reports (Peak Amplitude - Period 1 Amplitude) across market experiments by treatment: (Peak Amplitude - Round 1 Amplitude).

\section{Panel A: Magnitude by Treatment}

\begin{tabular}{llll}
\hline Treatment & N & Mean & SE \\
\hline & & & \\
Excitement & 24 & 292.0 & 17.1 \\
Calm & 15 & 163.3 & 12.9 \\
Fear & 16 & 218.2 & 25.3 \\
& & & \\
\hline
\end{tabular}

\section{Panel B: Peak Amplitude by Treatment}

\begin{tabular}{llll}
\hline Treatment & $\mathrm{N}$ & Mean & $\mathrm{SE}$ \\
\hline & & & \\
Excitement & 24 & 512.3 & 30.2 \\
Calm & 15 & 332.3 & 27.0 \\
Fear & 16 & 414.7 & 37.1 \\
& & & \\
\hline
\end{tabular}

\section{Panel C: Round 1 Amplitude by Treatment}

\begin{tabular}{lrrr}
\hline Treatment & $\mathrm{N}$ & Mean & \multicolumn{1}{l}{ SE } \\
\hline & & & \\
Excitement & 24 & 72.0 & 18.9 \\
Calm & 15 & 10.9 & 15.1 \\
Fear & 16 & 4.0 & 26.8 \\
& & & \\
\hline
\end{tabular}


Panel D: Peak Amplitude minus Round 1 Amplitude by Treatment

\begin{tabular}{llll}
\hline Treatment & $\mathrm{N}$ & Mean & $\mathrm{SE}$ \\
\hline & & & \\
Excitement & 24 & 440.3 & 33.5 \\
Calm & 15 & 321.4 & 30.3 \\
Fear & 16 & 410.7 & 25.8 \\
& & & \\
\hline
\end{tabular}


Table 2. Assessment of Emotional Reactions to the Videos

Table 2 reports the distribution of survey results on emotional reactions to 6 videos $(n=185)$. Each participant was randomly assigned to one of the six video clips. After watching a video clip, each participant was asked to choose (Panel A) the valence of his or her emotional reaction to the video on a five point scale; (Panel B) the intensity of his or her emotional reaction to the video on a five point scale; and (Panel C) which of six descriptions of emotional experiences best captured his or her feelings while watching the video (Afraid/Scared/Anxious, Bored/Jaded/Uninterested, Neutral/No Emotional

Reaction, Excited/Eager/Enthusiastic, Sad/Gloomy/Depressed, and Calm/Relaxed/Peaceful).

Panel A. Valence of the Video Clips ( 1 = Cleary Positive; $5=$ Clearly Negative $)$

\begin{tabular}{lllccc} 
& & & \multicolumn{2}{c}{$\begin{array}{c}\text { 2-tail } t \text { tests comparing the Exciting } \\
\text { videos to the alternative videos }\end{array}$} \\
\hline Knight \& Day & N & Mean & SD & Knight \& Day & Mr. \& Mrs. Smith \\
Mr. \& Mrs. Smith & 30 & 2.43 & 0.97 & & \\
Salem's Lot & 28 & 3.51 & 0.96 & -0.08 & $-1.38^{* * *}$ \\
Hostel & 32 & 4.53 & 0.84 & $-2.10^{* * *}$ & $-2.02^{* * *}$ \\
Franklin & 26 & 2.11 & 0.82 & 0.32 & $0.40^{*}$ \\
Peace in the Water & 38 & 1.68 & 0.81 & $0.75^{* * *}$ & $0.83^{* * *}$ \\
\hline
\end{tabular}

Note: The numbers in the last two columns indicate the differences defined as means of (column - row). $*_{0.10}$ significance; $* * 0.05$ significance; $* * * 0.01$ significance. For example, Peace in the Water is more positive than Franklin and Hostel is more negative than Knight \& Day.

Panel B. Intensity of the Video Clips (1 = Very Intense; $5=$ Not Intense At all)

\begin{tabular}{llcccc} 
& & & \multicolumn{2}{c}{$\begin{array}{c}\text { 2-tail } t \text { tests comparing Exciting } \\
\text { videos to the alternative videos }\end{array}$} \\
\hline Knight \& Day & N & Mean & SD & Knight \& Day & Mr. \& Mrs. Smith \\
Mr. \& Mrs. Smith & 31 & 2.16 & 1.05 & & \\
Salem's Lot & 28 & 2.29 & 1.00 & -0.12 & 0.11 \\
Hostel & 32 & 1.56 & 0.87 & $0.60^{*}$ & $0.73^{* * *}$ \\
Franklin & 26 & 3.27 & 1.08 & $-1.10^{* * *}$ & $-0.98^{* * *}$ \\
Peace in the Water & 38 & 3.05 & 1.27 & $-0.89^{* * *}$ & $-0.76^{* * *}$ \\
\hline
\end{tabular}

Note: The numbers in the last two columns indicate the differences defined as means of 
(column - row). ${ }^{*} 0.10$ significance; $* * 0.05$ significance; $* * * 0.01$ significance. For example, Hostel is more intense than Salem's Lot and Peace in the Water is less intense than Mr. \& Mrs. Smith.

\section{Panel C. Distribution of Most Representative Emotional Reaction by Video Clip}

\begin{tabular}{|c|c|c|c|c|c|c|c|}
\hline & \multicolumn{7}{|c|}{ Reported emotional reaction } \\
\hline & $\mathrm{N}$ & $\begin{array}{l}\text { Afraid/Scared } \\
\text { /Anxious }\end{array}$ & $\begin{array}{l}\text { Bored/Jaded } \\
\text { /Uninterested }\end{array}$ & $\begin{array}{c}\text { Neutral } \\
\text { (no emotional } \\
\text { reaction) }\end{array}$ & $\begin{array}{l}\text { Excited/Eager } \\
\text { /Enthusiastic }\end{array}$ & $\begin{array}{l}\text { Sad/Gloomy } \\
\text { /Depressed }\end{array}$ & $\begin{array}{l}\text { Calm/Relaxed } \\
\text { /Peaceful }\end{array}$ \\
\hline Knight \& Day & 30 & 3 & 4 & 2 & 20 & 0 & 1 \\
\hline Mr. \& Mrs. Smith & 31 & 2 & 8 & 2 & 17 & 0 & 2 \\
\hline Salem's Lot & 28 & 19 & 2 & 2 & 3 & 1 & 1 \\
\hline Hostel & 32 & 25 & 0 & 3 & 0 & 4 & 0 \\
\hline Franklin & 26 & 0 & 4 & 3 & 6 & 1 & 12 \\
\hline Peace in the Water & 38 & 1 & 1 & 2 & 1 & 1 & 32 \\
\hline
\end{tabular}

Note: The shaded cells in Panel $\mathrm{C}$ represent the modal choices made by the participants for each of the 6 video clips. 


\section{Appendix A - Asset-Pricing Market}

\section{A. Instructions}

This is an experiment in market decision making. You will be paid in checks for your participation at the end of the experiment. Different participants may earn different amounts. What you earn depends on your decisions and the decisions of others.

The experiment will take place through computer terminals at which you are seated. If you have any questions during experiment, raise your hand and a monitor will come by to answer your question.

\section{The Situation}

In this experiment, each participant will be given some Cash and Shares at the beginning.

When the experiment starts, you will participate in a market where Shares can be bought and sold between participants. You pay out of your Cash when you buy a share, and you get Cash when you sell a share.

The experiment is divided into $\mathbf{1 5}$ consecutive trading Rounds. Within each round, the market is open for trading Shares.

Shares will earn the owners a cash income called Dividend. At the end of EACH round, EACH share will pay the owner a dividend. The dividend per round can be $\mathbf{0 , 8}, \mathbf{2 8}$ or 60 cents, with equal chances. The dividends will be added to your cash amount immediately.

At the end of 15th round, a final dividend will be paid to the owner. Once that dividend is paid, the shares will be worth nothing. Your earnings will be based on the amount of cash that you accumulate. You can accumulate cash by buying and selling shares, and/or by holdings shares and collecting dividends.

Since $(0+8+28+60) \div 4=24$, the average dividend per round per share is 24 cents. That is, over many rounds, the average dividend per round tends to be 24 cents per share.

If you hold a share from round 1 to round 15 , the share will pay you 15 dividends. The total dividend value you receive can be as low as 0 cents $(15 \times 0=0)$. This would be the result if all 15 of the dividends are 0 . The total can be as high as 900 cents $(15 \times 60=$ 900 ), if all 15 of the dividends are 60. Given that each possible dividend has an equal chance of occurring each round, the average total dividend value tends to be 360 cents $(15 \times 24=360)$.

If you purchase a share in the 2nd round and hold it until the end of the 15th round, the average total dividend value will be 336 cents $(14 \times 24=336)$, and the total dividend could be as low as 0 cents $(14 \times 0)$ and as high as 840 cents $(14 \times 60)$. 
Similarly, if you hold a share for any number of rounds, $\boldsymbol{n}$, the share may return a dividend of as little as 0 cents or as much as $\boldsymbol{n} \times 60$ cents. The average dividend total tends to be $\boldsymbol{n} \times 24$ cents.

When a round is over, your Cash and Shares will carry over to the next round.

\section{How to Trade Shares?}

Within each round, participants can buy or sell shares from one another by making offers to buy or to sell. First, let's see how offers are shown in the market.

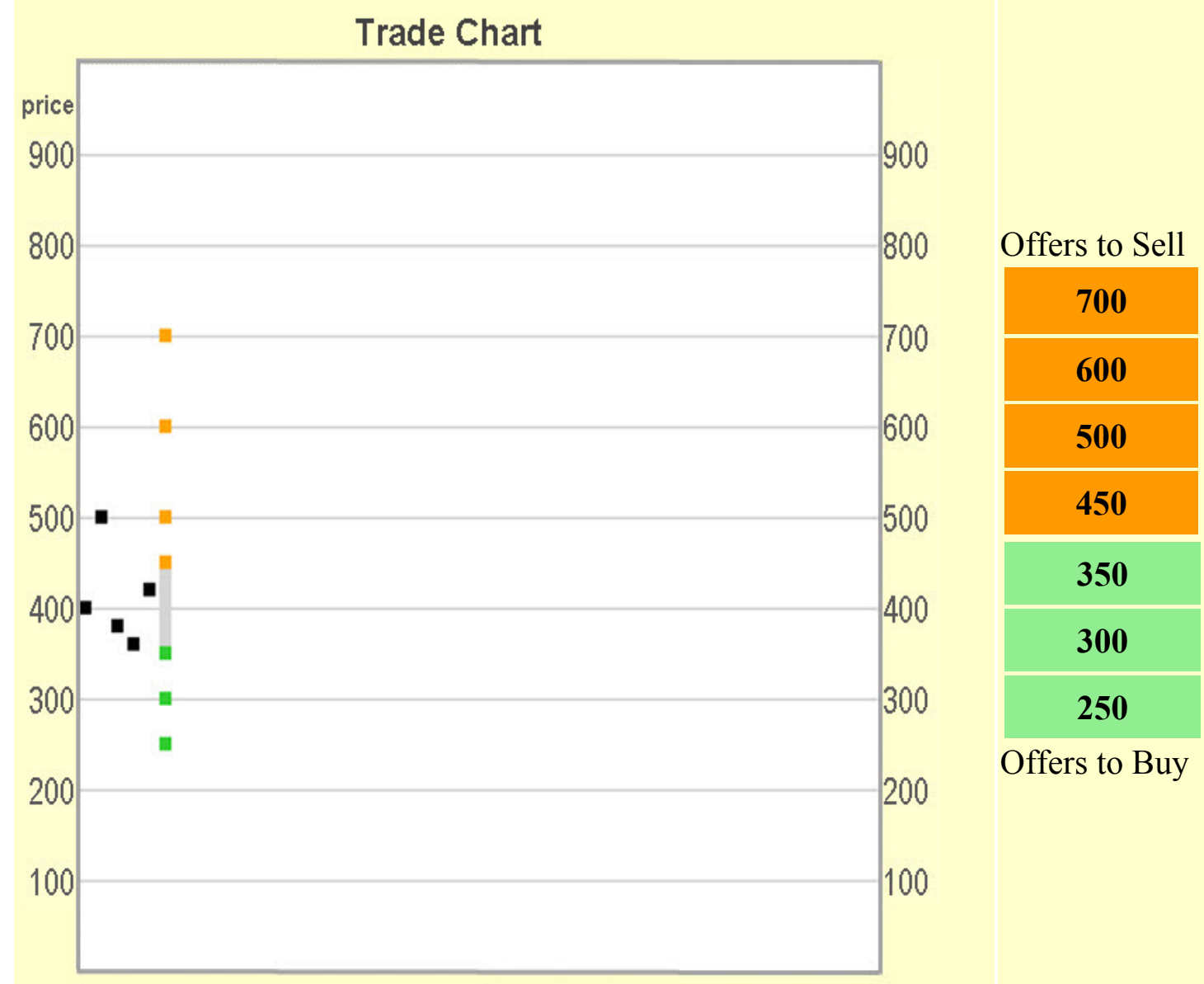

Every time someone makes an offer to buy a share at a certain price, a GREEN dot will appear on the Trade Chart. Every time someone makes an offer to sell at a certain price, an ORANGE dot will appear on the Trade Chart. Once a trade is actually made, the trade will be shown as a BLACK dot on the Trade Chart. For example, right now shown on the Trade Chart, five trades that have taken place are: 400, 500, 380, 360 and 420. 
Next to the Trade Chart, the Offers to Buy will be listed in increasing order, while the Offers to Sell will be listed in decreasing order. For example, the Offers to Sell are now 700, 600, 500 and 450; and the Offers to Buy are now 350, 300 and 250.

\section{Orders}

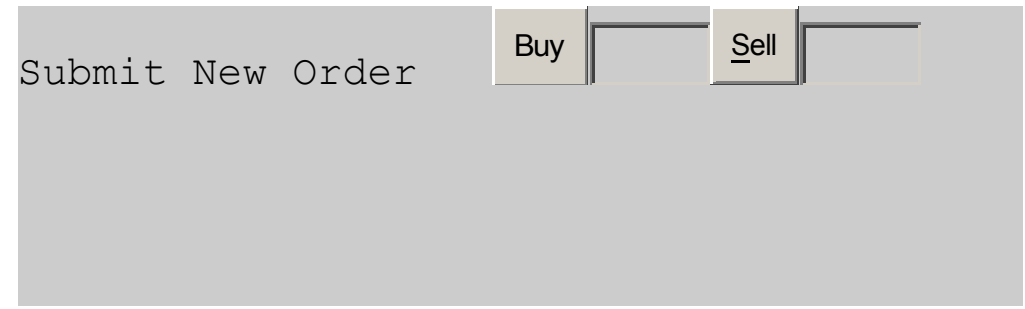

Offers are made through "Orders" Section. To enter a new offer to buy, type your buying price next to "Buy" button on the "Submit New Order" row, and click "Buy" button to submit your offer.

To enter a new offer to sell, type your selling price next to "Sell" button on the "Submit New Order" row, and click "Sell" button to submit your offer.

\section{Orders}

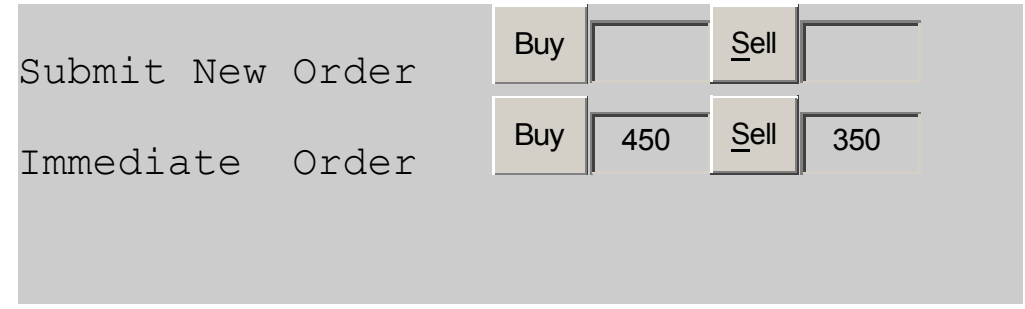

In the "Orders" section, the second row is "Immediate Order", where you can accept existing offers in the market.

The "Buy" box shows you the lowest offer you can buy from at the point of time. For example, the price showing right now is 450 . This indicates the best selling offer in the market is now 450. If you click on the "Buy" button next to it, you will immediately buy a share at the price of 450 .

The "Sell" box shows you the highest offer you can sell to at the point of time. For example, the price showing right now is 350 . This indicates the best buying offer in the market is now 350. If you click on the "Sell" button next to it, you will immediately sell a share at the price of 350 .

\section{Cancel Orders}


Click on an order to Cancel it

500

Whenever you enter new offers to buy, or sell, you will have those offers appear as buttons under "Cancel Orders" section. By clicking on these buttons, you can take them out of the market. For example, it is showing right now that you have an offer at 500. If you click on the button, you withdraw your offer at the price.

\section{Examples}

Let's see an example of a trade below. Note that the prices here are arbitrarily chosen and are irrelevant to the actual prices that will happen in the experiment.

Suppose you have 3 shares and 1050 in Cash at the start of a round, and you make one transaction purchasing a share for 420 cents within the round. If the dividend for the round is 60 cents, then:

Your share holdings will increase from 3 to 4 units.

You will pay 420 out of your Cash holdings, and for the round you will receive a total dividend of $(60 \times 4$ shares $)=240$. Thus your cash will decrease by $(420-240)=180$ cents. Your new cash holding will be $(1050-180)=870$ cents.

Another example:

Following the previous example, you now have 870 cash and 4 shares. Suppose in the next round you make two transactions. You sell one share for 300 and another share for 350. If the dividend for the round is 8 , then:

Your share holdings will, decrease from 4 to 2 units.

You get $(300+350)=650$ from your sales of 2 shares, and you will receive a total dividend of $(2$ shares $\times 8)=16$. Your Cash holdings will increase by $(650+16)=666$ cents. Your new cash holding will thus be $(870+666)=1536$ cents.

\section{Practice Session}

This experiment will last for 15 rounds. Each round will last for 3 and half minutes.

Before the actual 15 rounds start, we will give you a Practice Session, during which you can practice making offers and making transactions.

When the Practice Session is over, it will take some time to re-initialize and configure the trading program. The preparation could take around 5 to 8 minutes.

[Below, we introduce why we would play the video.] 


\section{[Same Video within treatment]}

Because the waiting is a bit long, we will play a video clip. We intend to use the video in another experiment and want to get some feedback from you. After you've finished watching the clip, please answer a few questions about it. Note that the video is not related to your earnings today. So thank you in advance for helping out.

\section{[Two Videos within treatment]}

Because the waiting is a bit long, we will play some video clips. Since we intend to use the videos in another experiment, we've selected a few different video clips. You will be randomly assigned to one of them. After you've finished watching the clip, please answer a few questions about it. Note that the video is not related to your earnings today. So thank you in advance for helping out.

In the main task, a short survey followed the emotion induction to check the manipulation. As you can see below, this emotion induction check varied by treatment and sometimes within a given treatment (by video clip). Hence, as described in the main text, a separate but standard emotion induction check was conducted to assess valence, intensity, and emotion type (see Appendix B).

After watching the videos, participants answered the following questions.

Questions asked after Mr. \& Mrs. Smith and after Franklin

1. How did this movie clip make you feel (from $1=$ very calm/relaxed to $9=$ very active/excited)

2. Do you think this clip is a nice filler task to be used in future experiments?

No_Yes

Questions asked after participants watched Knight \& Day, Salem's Lot, or Hostel

1. Please indicate (a) the emotional state that BEST describes what you've experienced while watching the video clip--only one option allowed. Then, indicate the intensity of the selected emotional experience.

Anxiety/Fear/Nervousness __ $(1=$ very little; $9=$ very much $)$

Excitement/Pleasure/Enthusiasm ___ $(1=$ very little;9=very much $)$ 
2. Do you think this clip is a nice filler task to be used in future experiments?

_No_Yes

Questions asked after participants watched "Mr. \& Mrs. Smith + Knight \& Day", and "I am Sam + The Champ" (see footnote 3 in the main text)

1. Please indicate the emotional state that BEST describes what you've experienced while watching the video clip--only one option allowed. Then, indicate the intensity of the selected emotional experience.

_Sadness/Distress/Unhappiness __ (1=very little; $9=$ very much $)$

_Excitement/Pleasure/Enthusiasm __ (1=very little; 9=very much $)$

2. Do you think this clip is a nice filler task to be used in future experiments?

_No_Yes

Questions asked after participants watched "Peace in the Water"

1. Please indicate if the video you've just watched was either pleasant or unpleasant--only one option allowed.

_Pleasant

Unpleasant

2. How did this movie clip make you feel (from $1=$ very calm/relaxed to $9=$ very active/excited)?

\section{Feedback}

(Please provide us some feedback on today's experiment. Thank you in advance!)

Q1: What is the purpose of the study?

Q2: What was your strategy in the experiment? 
Q3: Did you ever buy shares at prices above the remaining average dividend value? If so, what is your reason?

Q4: Did you encounter any difficulty in the experiment?

\section{Summary}

1. You will be given an initial amount of Cash and Shares at the very beginning.

2. Each share pays the owner a dividend of either $0,8,28$ or 60 cents at the end of EACH of the 15 trading rounds. The dividend amounts have the same chance of being drawn at the end of a round. Thus, the average dividend per round per share is 24 cents. Between rounds, you will be given some short time to review your holdings.

3. You can submit offers to BUY shares and offers to SELL shares.

4. You can make immediate trades by buying at the current lowest offer to sell or selling at the current highest offer to buy.

5. The market lasts for 15 rounds. At the end of round 15 , there will be one last dividend payment. After that the share expires and is worth nothing to you.

6. We will give you a Practice Session whereby you become familiar with the trading program. After that we will re-initialize the program and get ready for the actual session.

The instructions are over. If you have any question, raise your hand and consult the monitor. Otherwise, click "Start", login with the "Account Name" on the note on your desk, and wait for the Practice Round. 


\section{Appendix B - Emotion Induction Check}

$\underline{\text { Screen } 1}$

Main Task

On the following screen, you will be asked to watch a movie clip. After that, a few specific questions about the video will be asked.

Please, click on the continue button and pay careful attention to the movie clip.

$\underline{\text { Screen } 2}$

\section{Emotional Reaction to the Video Clip}

Now please indicate on the two manikin-like scales below how you emotionally reacted to the video clip.

The overall emotional experience I felt while watching the video clip was...

Clearly Positive

Clearly Negative

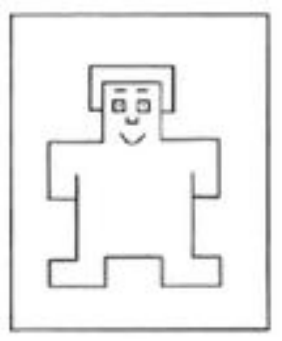

$\mathrm{O}$

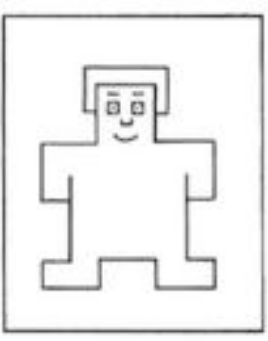

$\mathrm{O}$

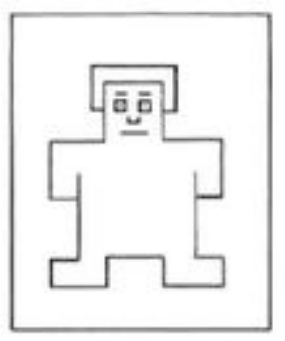

$\mathrm{O}$

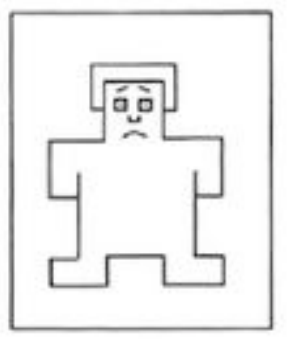

$\mathrm{O}$

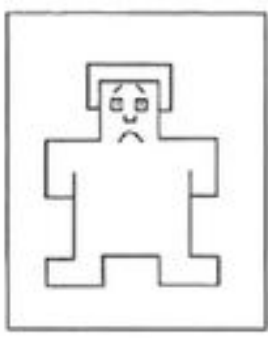

$\mathrm{O}$

The overall emotional experience I felt while watching the video clip was...

Very Intense

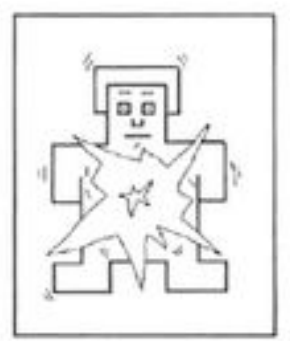

$\mathrm{O}$

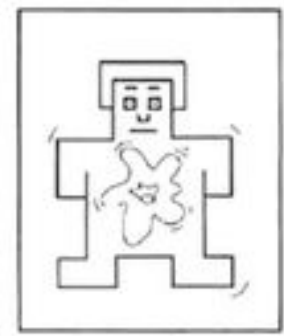

$\mathrm{O}$

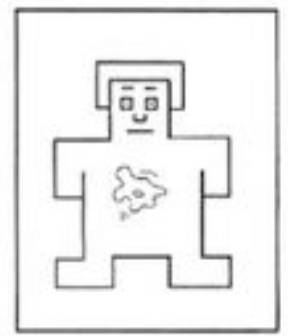

$\mathrm{O}$

Not Intense at All

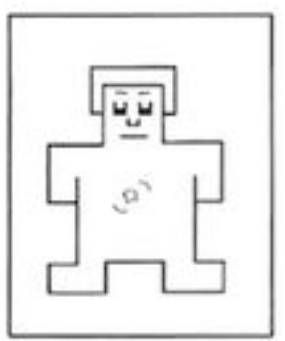

$\mathrm{O}$

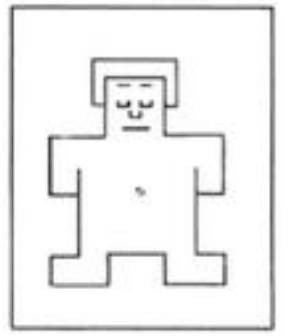

$\mathrm{O}$ 
Screen 3

\title{
Emotional Reaction to the Video Clip
}

Please indicate the emotion that best captures what you've felt while watching the movie clip.

ONLY ONE OPTION ALLOWED:

The movie clip made me feel....

\author{
Afraid/Scared/Anxious \\ Bored/Jaded/Uninterested \\ Neutral (no emotional reaction) \\ Excited/Eager/Enthusiastic \\ Sad/Gloomy/Depressed \\ Calm/Relaxed/Peaceful
}

Screen 4

What was the main story of the movie clip? Please describe it in detail.

Thank you! 